\title{
Application of Flipped Classroom in University Physics Experiment Yan-ping $\mathrm{LI}^{1}$, Zhong-ying YUAN ${ }^{2}$ \\ ${ }^{1}$ Basic Department of Liaoning Institute of Science and Technology, Liaoning, Benxi, China \\ ${ }^{2}$ School of Mechanical Engineering, Liaoning Institute of Science and Technology, Liaoning, Benxi, China
}

Keywords: Flipped Classroom; College Physics Experiment; Teaching Mode.

\begin{abstract}
Flipped classroom is a teaching mode that reverses the two stages in a traditional classroom, knowledge transfer and knowledge internalization, so as to reform traditional classroom teaching. This paper analyses the problems in the physics experiments of the university, introduces the theoretical basis of flipped classroom, discusses the construction of flipped classroom resources, and finally conducts the practice of flipped classroom mode in college physics experiment. It has a positive effect on improving students' self-learning ability, hands-on ability and innovation consciousness.
\end{abstract}

\section{Introduction}

Flipped classroom is a teaching mode by combining online learning and face-to-face learning. It has become increasingly popular in the United States.[1]The flipped classroom teaching mode has completely subverted the traditional teaching, truly gives the learning initiative to students, inspires their learning motivation, realizes students' personalized study, and improves the teaching effect. How to incorporate flipped classroom into college physics experiment teaching is a new topic for college physics experiment teaching.

\section{The Problems in the Physics Experiments of the University}

The use of fewer and fewer hours to develop students' increasingly strong hands-on ability is a big problem in front of every experimental teacher.

\subsection{The Teaching Mode is Unitary and Students Learn Passively}

In the traditional experimental teaching process, students prepare a lesson by textbook before class. Teacher explains, demonstrates and guides the students to complete the experiment. After the class, the students complete the experimental data processing, write the experimental reports and submit them to the experimental teacher for correction. During the experiment, the students can't experience the pleasure of finding and solving problems. For a long time, there has formed a phenomenon in which students completing the experiment mechanically in accordance with the steps arranged by the teacher [2].

\subsection{Less Interactive Communication}

College physics experiments have a very high requirement for practical ability. Students will encounter a lot of unpredictable difficulties in preview before class and review after class. If they encounter problems, they will not be able to get guidance through communication immediately so that the progress will be slowed down and the quality of learning will be low too. When studying in class, students seldom ask in-depth questions proactively. What they ask are usually abnormal phenomena appearing in experiment so as to obtain experimental results, which belongs to shallow level of communication between students and teacher.

\section{The Theoretical Basis of Flipped Classrooms}

The activity theory of learning believes that learning is not a process of transmission, nor a 
process of reception. Learning is an intentional, positive, and self-consciously constructed practice process, including interactive intentions, actions, and reflections (JONASSEN, 2000).

\subsection{The Theory of Mastery Learning}

In 1976, the famous American psychologist and educator Bloom suggested that almost all students can master almost all the learning content as long as they are given enough time and received appropriate teaching. This is the theory of mastery learning.

The core idea of the mastery learning theory is to allow each student to have sufficient study time. This coincides with the basic idea of flipped classrooms, that is, teachers return learning time to students. Especially at the stage of knowledge transfer in a flipped classroom, students can arrange and control their own learning according to their own situation by using micro-lectures. They can skip the parts of videos they have understood, and replay and watch repeatedly what they don't understand, or stop to contemplate or take notes, so as to complete personalized learning3.

\subsection{Constructivist Learning Theory}

Learning is not simply a transfer of knowledge by teachers to students, but a process by which students construct the knowledge himself. Instead of simply passively receiving information, students actively construct the meaning of knowledge, a process which cannot be replaced by others.

Flipped classrooms are different from traditional ones. They return initiative in learning to students. The process of learning is a process of students constructing their own knowledge. Instead of trying to catch up with or waiting for teachers in traditional classrooms where teachers always take care of most of the students so that they can't pay much attention to the poorest ones as well as the best students, students in flipped classrooms first get the basics they need to know through videos, then their doubts about knowledge arising in the process of deepening understanding can be solved in the interaction with classmates and teachers in class.

In the learning process of most micro-course videos, students can choose emphases to watch, and decide watching times and speed based on their own need, so as to complete active information processing. When encountering incomprehensible knowledge points, they can also go back and watch the video repeatedly. Nevertheless, for students, this is still a traditional, unitary process of knowledge transmission and reception, lacking intentional, positive, and self-consciously constructed practices. It can't motivate students' actions and reflections, as well as their intentions for interaction. It will be a long-term development to transform the receptive learning of micro-course videos into learning activities with rich content, which includes interactions, actions and reflections. That is to say, in the application of flipped classrooms in university physics experiment courses, after students have learned the relevant principles of a physics experiment through micro-course videos, verified and applied experiments on this experiment will then be carried out, focusing on cultivating students' ability to convert the learned knowledge of physics into application.

\section{The Construction of Flipped Classroom Resources}

\subsection{Making Video of Micro-lecture and Completing the Knowledge Transfer before Class}

Each experiment design in the university physics experiments is made into a series of short videos, which are divided into videos for experimental background, experimental purpose, experimental principle, experimental instruments introduction and experimental operation. With strong pertinence, they are convenient for students to learn.

\subsection{Compiling and Publishing Stereoscopic Textbooks}

In order to cooperate with the implementation of the flipped classroom teaching mode, we have written a three-dimensional textbook for university physics experiments, which has been published by Mechanical Industry Press. The published textbook has provided the necessary foundation for the implementation of flipped classroom. 
The two-dimensional codes are added in the textbook where special explanations are needed. When students prepare a class, they can use their mobile phones to scan the QR code and get access to the book chain. On which, you can find the micro-course videos recorded by the teacher in advance and start to learn, thus realizing on-demand learning and learning at any time.

\section{The Practice of the Flipped Classroom Teaching Mode}

\subsection{Preview before Class}

Students preview through textbook, the micro-lecture videos and other learning resources. Students need to submit their preview reports in class and feedback the doubts they have in preview to teachers so that the teachers can master the students' previews in a timely manner.

\subsection{Internalization of Knowledge in Class}

In class, students complete experiments independently, and teacher no longer teaches the content of the class. At this stage, the teacher encourages the students to find problems in a experiment, and ask questions, and guide the students to solve the problems by themselves, so as to cultivate the students' ability to think. In the whole experimental class, the teacher uninterruptedly understands the students' experimental situation, finds out the problems that the students find in the preview or in the experiment, corrects the students' experimental plans in time, and carries out the personalized guidance according to the students' problems.

\subsection{Many Kinds of Evaluation}

Teachers' evaluation of students runs through the entire teaching process, and good evaluation can supervise and strengthen students' learning. The teachers need to conduct multi-dimensional analysis and evaluation on students' previews, operations in class and after-class reports. Correct and appropriate student (peer) evaluations can also be great incentives for students' learning motivation [3].

\section{Summary}

In the university physics experiment teaching, the application of the flipped classroom mode has realized the transition from "teaching" to "learning"; changing students from "passive" learning to proactively "initiative" inquiry learning. Therefore, conducting the flipped classroom teaching mode in university physics experiments has a positive effect on improving students' self-learning ability, hands-on ability and innovation consciousness.

\section{References}

[1] Haihong Liu, American Universities' Flipped Classroom Teaching Model for the Curriculums of Social Science [J]. China Higher Education Research, 2016, (8): 89-92.

[2] Chaozheng He, Haizhen Song, Hongjun Zhang, Application of flipped classroom model based on microlecture in the teaching of college physics experiments [J]. Journal of Nanyang Normal University, 2017, 16 (03): 47-49.

[3] http://wk.eastedu.com/SucceedCase_Detail_1.html

[4] Qingzhou Wu, Tao Wang, Research and practice of the teaching model of innovative physics experiment base on MOOC [J]. Physics Experimentation, 2017, 37 (08): 40-43+47. 